\title{
Watching the Games: public health surveillance for the Sydney 2000 Olympic Games
}

\author{
L R Jorm, S V Thackway, T R Churches, M W Hills
}

J Epidemiol Community Health 2003;57:102-108

Study objective: To describe the development of the public health surveillance system for the Sydney 2000 Olympic Games; document its major findings; and discuss the implications for public health surveillance for future events.

Design: Planning for the system took almost three years. Its major components included increased surveillance of communicable diseases; presentations to sentinel emergency departments; medical encounters at Olympic venues; cruise ship surveillance; environmental and food safety inspections; sur-

See end of article for authors' affiliations veillance for bioterrorism; and global epidemic intelligence. A daily report integrated data from all sources.

Correspondence to: Dr L R Jorm, Epidemiology and Surveillance Branch, New South Wales Health Department, Locked Bag 961, North Sydney NSW 2059, Australia;

ljorm@doh.health.nsw.gov.au

Accepted for publication 27 June 2002

Setting: Sydney, Australia. Surveillance spanned the period 28 August to 4 October 2000.

Participants: Residents of Sydney, athletes and officials, Australian and international visitors.

Main results: No outbreaks of communicable diseases were detected. There were around $5 \%$ more presentations to Sydney emergency departments than in comparable periods in other years. Several incidents detected through surveillance, including injuries caused by broken glass, and a cluster of presentations related to the use of the drug ecstasy, prompted further action.

Conclusions: Key elements in the success of public health surveillance for the Games included its careful planning, its comprehensive coverage of public health issues, and its timely reporting and communication processes. Future systems need to be flexible enough to detect the unexpected.

$\mathrm{T}$ he Games of the XXVI Olympiad, held in Sydney in September 2000, was the largest event ever held in Australia. Around 11000 athletes from 200 countries, 5100 officials, 11000 media personnel, and 100000 international visitors converged on Sydney, the capital city of the state of New South Wales. Sydney has a usual population of just under four million people. Huge crowds watched the sporting events - the main Olympic stadium held 110000 peopleand participated in Olympic related festivities and cultural events across the city. An estimated 1.5 million people congregated around Sydney Harbour for the closing night celebrations.

The sheer scale of the Sydney 2000 Olympic Games presented a major challenge for the local public health system. Amplification of the usual health risks posed by communicable and food borne diseases, environmental hazards, and risky personal behaviours-and the possibility of biological terrorist (bioterrorist) attack-meant that improved early warning and monitoring systems for public health issues were needed.

Increased public health surveillance was first described for the 1984 summer Olympic Games in Los Angeles. ${ }^{1}$ For the 1992 Barcelona Olympic Games, modifications were made to the existing surveillance system for communicable diseases. ${ }^{2}$ Before Sydney, the most comprehensive public health surveillance system was that deployed for the 1996 Centennial Olympic Games in Atlanta. Its key components were augmented laboratory surveillance for communicable diseases, a system to monitor all emergency encounters at eight sentinel hospitals, and a system to enumerate medical encounters in Olympic venues. ${ }^{34}$

This paper reports how the public health surveillance system for the Sydney 2000 Olympic Games was developed; describes the surveillance system itself; documents its major findings; and discusses the implications for public health surveillance for future similar events.

\section{METHODS}

Planning the surveillance system for the Sydney 2000 Olympic Games

The New South Wales Health Department was responsible for providing public health services during the Sydney 2000 Olympic Games. Surveillance was recognised as a priority from the commencement of planning for the public health aspects of the Games in late 1994. The department's representative at the 1996 Centennial Olympic Games in Atlanta observed the surveillance system and obtained documentation from the Georgia Department of Human Resources' Division of Public Health.

The major public health issues managed in the three previous summer Games were heat related illness, ${ }^{13}$ food safety, ${ }^{23}$ and bombing related injuries resulting from terrorist attack. ${ }^{3}$ In 1997, the health department conducted a risk assessment to prioritise public health issues for the Sydney Games. The issues identified were: food borne illness, terrorism (from conventional means), measles, rubella, pertussis, meningococcal and viral meningitis, tuberculosis, sexually transmitted diseases, viral haemorrhagic fevers, blood borne pathogens, water borne illness, and Legionnaires' disease. Heat related illness was considered unlikely to be a major problem in Sydney in September.

A set of priority public health interventions and services was developed from this list. However, during the next three years, the perceived importance of risk events changed. During early 1998, an outbreak of cryptosporidiosis associated with recreational swimming pools in Sydney highlighted the importance of swimming pool safety. ${ }^{5}$ In mid-1998, Giardia cysts and Cryptosporidium oocysts were reported to be present in the main Sydney metropolitan water supply. ${ }^{6}$ While not giving rise to any disease outbreak, this incident confirmed the importance of surveillance for water borne disease. An outbreak of Legionnaires' disease in the state of Victoria in 1998, which generated high levels of community concern, ${ }^{7}$ reinforced the importance of that issue. 
Table 1 Emergency department surveillance during the Sydney 2000 Olympic Games. Target presentations by condition, 28 August-04 September 2000

\begin{tabular}{|c|c|c|c|c|c|}
\hline \multirow{3}{*}{ Condition } & \multicolumn{5}{|c|}{ Number of presentations (\%) } \\
\hline & \multirow{2}{*}{$\begin{array}{l}\text { Pre-competition period } \\
\text { (28 Aug-14 Sept 2001) } \\
3030(50.9)\end{array}$} & \multirow{2}{*}{$\begin{array}{l}\begin{array}{l}\text { Competition period } \\
\text { (15 Sept-01 Oct 2001) }\end{array} \\
3038(51.9)\end{array}$} & \multirow{2}{*}{$\begin{array}{l}\text { Post-competition period } \\
\text { (02 Oct-04 Oct 2001) } \\
572(60.1)\end{array}$} & \multicolumn{2}{|c|}{$\begin{array}{l}\text { Total surveillance } \\
\text { period }\end{array}$} \\
\hline & & & & 6640 & (52.1) \\
\hline Vomiting & $1578(26.5)$ & $1536(26.3)$ & $207(21.7)$ & 3321 & $(26.0)$ \\
\hline Pneumonia & $1684(28.3)$ & $1272(21.7)$ & $152(16.0)$ & 3108 & $(24.4)$ \\
\hline Diarrhoea & $946(15.9)$ & $960(16.4)$ & 119 (12.5) & 2025 & $(15.9)$ \\
\hline Influenza-like illness & $467(7.8)$ & $404(6.9)$ & $31(3.3)$ & 902 & (7.1) \\
\hline Illicit drug related & $148(2.5)$ & $193(3.3)$ & $54(5.7)$ & 395 & $(3.1)$ \\
\hline Febrile illness with rash & $92(1.5)$ & $74(1.3)$ & $7(0.7)$ & 173 & (1.4) \\
\hline Meningitis & $34(0.6)$ & $25(0.4)$ & $8(0.8)$ & 67 & (0.5) \\
\hline Bloody diarrhoea & $44(0.7)$ & $15(0.3)$ & $3(0.3)$ & 62 & (0.5) \\
\hline Pertussis & $15(0.3)$ & $11(0.2)$ & $1(0.1)$ & 27 & (0.2) \\
\hline Acute viral hepatitis & $10(0.2)$ & $6(0.1)$ & $1(0.1)$ & 17 & $(0.1)$ \\
\hline Other (Olympic family members only) & $38(0.6)$ & $130(2.2)$ & $4(0.4)$ & 172 & (1.3) \\
\hline Total* & $5954(100)$ & $5849(100)$ & $952(100)$ & 12755.0 & $0)$ \\
\hline
\end{tabular}

One issue not directly considered in the 1997 risk assessment was that of a deliberately introduced epidemic arising from an act of bioterrorism, a scenario that was discussed in the post-Games reports from Atlanta. ${ }^{3}$ Subsequently, contingency plans for such scenarios were incorporated in to Olympic planning.

Detailed planning for disease surveillance started in October 1997. By July 1998, the overall design of the surveillance system was mapped out. Components of the system were trialled during mass gatherings in 1999 and early 2000, including Olympic test events, New Year's Eve 19992000, and the Sydney Gay and Lesbian Mardi Gras 2000. A full dress rehearsal of the emergency department component of the system was undertaken in May 2000.

\section{Surveillance system objective}

The objective of the public health surveillance system for the Sydney 2000 Olympic Games was to quickly detect emerging disease outbreaks or unusual patterns of disease or injury that might require rapid intervention immediately before, during, and after the Games.

\section{Surveillance period}

The surveillance system for the Sydney 2000 Olympic Games operated over a 38 day period (28 August-4 October 2000), starting three weeks before the Games opening ceremony and finishing three days after the closing ceremony. Some components of the system operated for only part of this period, because they were linked with the operation of Olympic venues.

\section{System components}

The system had the following major components:

\section{Enhanced surveillance of communicable diseases}

In New South Wales, medical practitioners, hospitals, laboratories, schools, and child care centres are required by law to notify certain communicable diseases to the health department, usually via a local public health unit. Notification data are entered into a local database in each public health unit and forwarded daily to a central database.

For the Sydney 2000 Olympic Games, this existing system was enhanced by instituting "active" surveillance and increasing the frequency of data transfer, to three times daily. Local public health units across Sydney contacted laboratories each day to seek information on new diagnoses of 22 high priority communicable diseases. Emergency procedures for data entry and communication were developed in case of computer network failure. ${ }^{8}$
The Games period coincided with the tail end of the "influenza season" in New South Wales. Data from the routine system for surveillance of influenza-comprising reports of clinical influenza-like illnesses from sentinel general practitioners and reports by hospital laboratories of influenza diagnoseswere monitored on a weekly basis.

\section{Presentations to sentinel emergency departments}

Fifteen emergency departments across Sydney were selected as sentinel sites for surveillance of high priority target conditions (table 1). These managed about $80 \%$ of all emergency presentations in metropolitan Sydney and served the geographical areas where the main Olympic venues and entertainment sites were located. The health department supplied funds to employ surveillance officers, a desktop computer, purpose built database software, documentation, and training.

To ascertain target cases, triage nurses identified patients reporting relevant symptoms at presentation, and surveillance officers scanned the existing routine electronic data collection system, paper based patient records, and emergency department log books. Up to four conditions were recorded for each target case. Other information collected included time and date of presentation, date of birth, sex, country of residence, whether the case was part of a suspected outbreak, injury cause, injury intent, and (up to four) drug types. For injuries, a text description of how and where the injury occurred was entered in a free text data field.

Data on all presentations up to 2400 hours were entered locally onto the database and transferred electronically to the health department by 0800 each morning.

\section{Medical encounters at Olympic venues}

The Sydney Organising Committee for the Olympic Games (SOCOG), under the aegis of the International Olympic Committee (IOC) Medical Commission, was responsible for organising appropriate medical services at Olympic venues, including specialist sports medicine facilities for athletes and general medical facilities accessible to spectators, staff, officials, SOCOG volunteers and others at competition venues.

Olympic medical facility staff recorded information on every encounter on a standard form, which captured information about the patient, the nature of their health problem, and the circumstances in which injuries occurred. Forms were faxed daily to SOCOG headquarters for entry into a central database. Each evening, these data were used to generate a surveillance report for the health department that focused on public health issues, particularly food related 
illness, communicable diseases, and injuries suffered by spectators at Olympic venues. A separate report, in French and English, was also generated from the same data for consideration by the IOC Medical Commission each evening.

\section{Cruise ship surveillance}

Ten cruise ships were berthed in Sydney during the Games, acting as floating hotels. In accordance with New South Wales law, cruise ship doctors were required to advise the health department of cases of notifiable diseases. Additionally, they completed a daily medical report on the number of people presenting with influenza-like illness, suspected pneumonia or gastroenteritis, hospital admissions, and deaths.

The vessel inspection programme for the Games was built upon the existing programme, which was modelled on the US Centres for Disease Control and Prevention (CDC) Vessel Sanitation Program. ${ }^{10}$ Environmental officers conducted inspections of each cruise ship upon arrival and regularly thereafter, focusing on food buffet services (in particular, food temperatures), water supply, waste disposal, air conditioning systems, and swimming pool and spa maintenance.

Information on cruise ship health and environmental issues was faxed daily to the health department.

\section{Olympic venue food safety and environmental health inspections}

Throughout the Games, food safety teams at all Olympic venues conducted site inspections and selective sampling and microbiological testing of foods. Food outlets in the city are not usually subject to routine testing on this scale. Rather, routine inspections target premises that have been the subject of complaint, or where the operation is considered to be at high risk for breaches of food safety. At intervals, environmental health teams inspected water cooling systems, waste services, sanitation, and general safety matters inside the venues.

Each day, the food safety and environmental health teams faxed summary reports giving the number and nature of inspections performed, and details of any unsatisfactory findings, to the health department.

\section{Surveillance for bioterrorism}

Models for surveillance of bioterrorism emphasise the need for the early identification of the unusual occurrence of nonspecific respiratory or gastrointestinal illness, with the incidence of influenza-like illness being a possible clue to a covert release in the earliest stage. ${ }^{112}$ Accordingly, the incidence of influenza-like illness and pneumonia was reviewed daily during the surveillance period, using data from the emergency department surveillance system in combination with the other point of care data (hospital transfers, cruise ship consultations, and Olympic venue medical services).

Prior to the Games, training in awareness for chemical, biological, and radiological emergencies took place across the state of New South Wales. Seven hospital sites developed mass casualty decontamination facilities with additional procedures implemented at five other hospitals. Protective equipment and pharmaceutical supplies were distributed to the major hospital sites.

\section{Global epidemic intelligence}

During the surveillance period, relevant web sites and email discussion groups were scanned for information on current communicable disease outbreaks occurring around the world.

\section{Surveillance reporting cycle}

The New South Wales Health Olympic Coordination Centre, within the health department, was the key mechanism for coordinating public health action during the Games, and the central point of contact with other government agencies. A separate, but linked, Health Services Disaster Control Centre also operated continuously, and Disaster Response Teams were on call at all times. A 24 hour Olympic Agency hotline permitted active liaison with organisations such as emergency services and police. Whole of government responses were coordinated at the Olympic Precinct and Regional Operations Centre and the State Emergency Operations Centre.

During the Games period, a daily briefing of key Health Olympic Coordination Centre staff was held at 1400 to review health activities and issues over the previous 24 hours and to determine priorities for the next 24 hours. The reporting cycle for the surveillance system was designed so that the report tabled at this briefing session was as current as possible. All reports were made available to authorised staff via a dedicated Olympic public health surveillance web site.

Each day over the surveillance period, data from all currently operating surveillance sources were received at the Health Olympic Coordination Centre, by 0800. Preparation of daily reports based on these data was highly automated, enabling surveillance staff to focus on interpretation of the data and additional, ad hoc analysis if required. A suite of programs was used to convert the surveillance data into SAS $^{13}$ datasets, from which draft reports for each element of the surveillance system were generated.

By 1100 each day a draft "top level" daily report, summarising the surveillance data for the previous 24 hours, was produced and available on the web site. This was reviewed at 1200 by an Olympic Surveillance Review Team, consisting of experts in public health and surveillance. After this review, a final version of the daily report was produced for the Health Olympic Coordination Centre briefing session at 1400.

\section{System resources}

During the surveillance period, four department of health staff and eight public health trainees worked full time on coordinating, collating, and analysing surveillance data, and preparing reports. About 50 surveillance officers were trained to collect emergency department data, and each emergency department was staffed by an officer for 18 hours each day, seven days per week. One hundred and fifteen officers were employed to conduct food safety and environmental health inspections in venues. Ten additional senior department of health staff participated in the daily Olympic Surveillance Review Team meetings.

\section{RESULTS}

\section{Enhanced communicable disease surveillance}

A total of 1740 cases of notifiable communicable diseases with onset during the surveillance period were reported among residents of Sydney. This was consistent with the number of reports in the corresponding periods in 1999 (1479) and 2001 (2143), given an underlying upward trend in notifications. Twelve cases of notifiable communicable diseases with onset during the surveillance period were reported among persons usually resident in other countries. This compares with six and seven cases, respectively, for the comparable periods in 1999 and 2001. All notifications were followed up according to established protocols, and no unusual patterns or disease clusters were detected.

Unlike the previous three years, the 2000 influenza season started late and there was no evidence of a decline in incidence by the first week of September. Furthermore, five days before the opening ceremony an investigation into a potential cluster of Legionnaires' disease on board one of the cruise ships destined to be an Olympic "floating hotel" identified influenza as the cause of the outbreak affecting over 50 passengers. ${ }^{14}$ These incidents prompted close scrutiny of emergency department presentations for influenza-like illness throughout the surveillance period. 


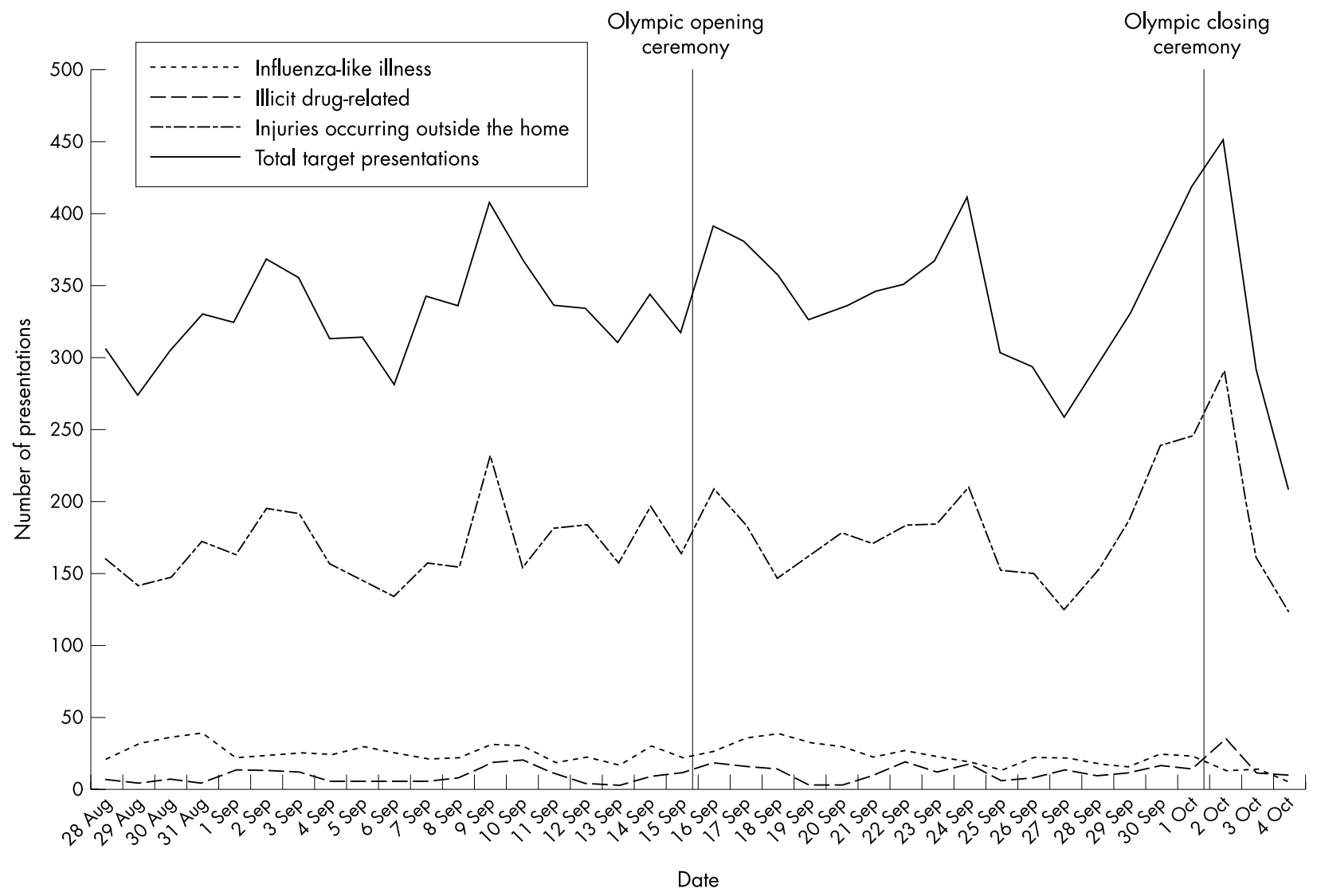

Figure 1 Emergency department surveillance during the Sydney 2000 Olympic Games. Target presentations for selected conditions 28 August to 4 September 2000.

\section{Emergency department presentations}

During the surveillance period, the 15 sentinel emergency departments recorded a total of 55339 presentations. This was around $5 \%$ greater than the number of presentations recorded in the corresponding 38 day periods in 1999 (51 117) and 2001 (53 173). Only a small minority of presentations (1431, or $2.7 \%)$ were by overseas visitors, but this proportion was slightly higher than in the corresponding periods in 1999 (1.5\%) and 2001 (1.9\%).

Almost one quarter of all presentations (12 755, 23.0\%) were for the Olympic surveillance target conditions ("target presentations") (table 1). There were similar numbers of target presentations in the two week period before the Games (mean 331 per day) and during the two weeks of Games competition (mean 344 per day) (fig 1). There were more target presentations on Saturdays and Sundays (mean 384 per day) than on weekdays (mean 318 per day). The number of target presentations peaked at 452 on Monday 2 October-the day immediately after the Games closing ceremony. The sharp decrease in presentations at the end of the surveillance period probably reflects decreased diligence on the part of surveillance officers during these final days.

Patient's country of residence was recorded for 11718 target presentations. Among these, 11213 (96\%) were Australian residents, $64(0.55 \%)$ were residents of the United States of America, 61 (0.52\%) were residents of the United Kingdom or Ireland, and $23(0.20 \%)$ were residents of New Zealand.

A breakdown of all target presentations by cause is given in table 1. Injuries occurring outside the home accounted for half of all target presentations ( 6640 or $52.0 \%$ ).

In general, the pattern of causes was similar in the pre-Games period and in the period of Games competition. However, the proportion of target presentations for bloody diarrhoea and pneumonia decreased slightly during the competition period. Conversely, the proportion of target presentations for illicit drug related causes increased slightly.

There were also some differences in the pattern of injuries. During the competition period, there were slightly more injuries attributed to being struck by or colliding with a person or object, and bicycle injuries. The proportion of injuries that were reported to be attributable to physical assault, sexual assault, or attempted suicide was similar during the preOlympic and competition periods. During the competition period, fewer injuries occurred in the work place and more on beaches or in swimming pools, and in premises licensed to sell alcohol, such as pubs, bars, and clubs.

Comparatively few injuries $(217$, or $3.3 \%)$ were reported to have occurred at Olympic venues or events. Some of the more unique Olympic related injuries included: shoulder strain incurred by an official while holding a flag in windy conditions during a rehearsal for the closing ceremony; an eye injury to an official caused by an Olympic identification pass that flicked upwards; bruising to a spectator caused by a hockey ball that hit him in the groin; and an elbow injury to a swimming spectator attributed to over-vigorous clapping.

The surveillance system was designed to capture all presentations by accredited Olympic family members to sentinel emergency departments, regardless of cause. Olympic family members accounted for a total of 225 presentations, comprising $72(32 \%)$ by athletes and $153(68 \%)$ by officials. Most of these presentations $(138$, or $61 \%$ ) were for conditions other than those specifically targeted for Olympic surveillance, while most of the remainder $(68$, or $30 \%)$ were for injuries. Thirty one Olympic athletes presented with injuries. Among these were seven athletes injured in falls from horses, four injured while participating in boxing, and three injured in falls from bicycles. 


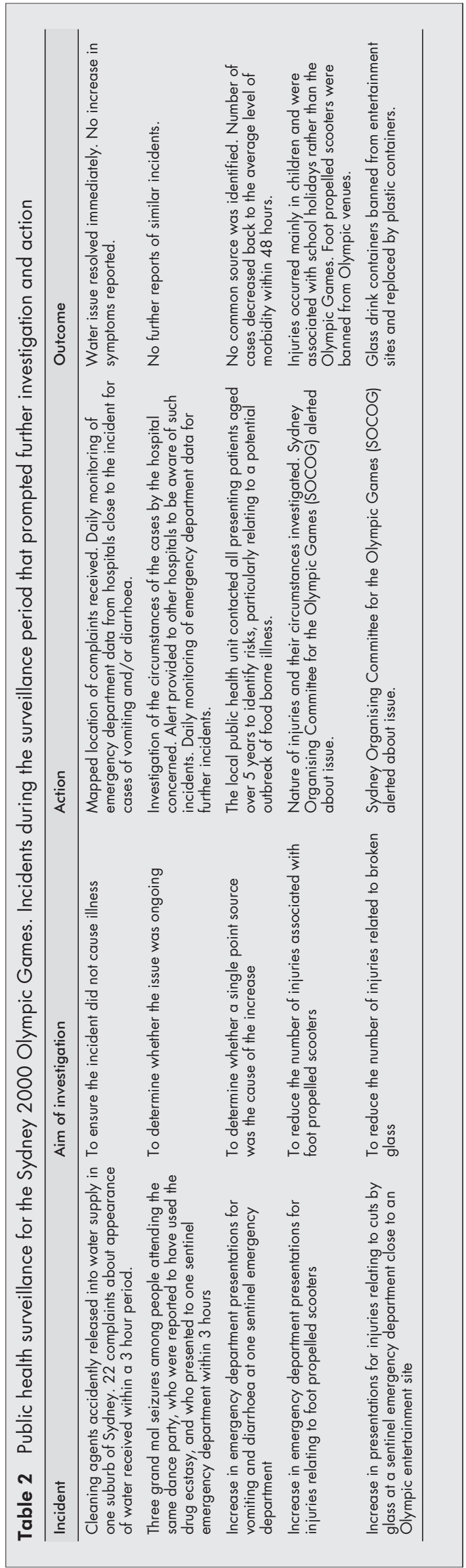

Medical encounters in Olympic venues

From the opening of the Olympic Village Polyclinic on 3 September 2000 until the close of operations on 4 October 2000, 12131 encounters were recorded by medical facilities at Olympic venues. Of these, $33 \%$ of presentations were by athletes, $29 \%$ by Olympic team officials and other Olympic family members, $17 \%$ by local Games workforce members, and $4 \%$ by media personnel. One third (36\%) of encounters were for musculoskeletal problems, primarily among athletes, and $9.3 \%$ and $4.1 \%$ were for non-acute optometry and restorative dental procedures respectively.

Presentations for upper and lower respiratory tract illness at Games medical facilities peaked at 90 per day on 16 September, the day after the opening ceremony, and declined throughout the rest of the Games period. By 18 September there had been 28 medical encounters among Olympic Village residents recorded as being for influenza-like illness. A review of the records for these cases undertaken on 19 September revealed that only three of these cases actually met the case definition for influenza-like illness. There were 47 presentations for sexually transmitted diseases and other genital disorders.

\section{Cruise ship surveillance}

During the period 11 September to 4 October 2000, up to 3440 passengers and 2902 crew were accommodated at any one time on the 10 cruise ships berthed in Sydney Harbour. Cruise ship doctors reported a total of 320 consultations by passengers and 844 consultations by crew. These included 28 cases of suspected influenza and 17 cases of gastroenteritis. Five passengers or crew were admitted to hospital.

Vessel inspection teams conducted 36 inspections of the 10 cruise ships. Nine of the 10 ships were given "satisfactory" ratings according to the vessel inspection programme. The teams identified several environmental and hygiene problems on the remaining ship, which was not regularly used as a passenger liner, prompting follow up inspections. The teams also identified issues relating to food buffet services on six of the ships, leading to follow up inspections.

\section{Olympic Venue food safety and environmental health inspections}

In the period 12 September to 30 September 2000, four of the 47 Olympic venues inspected received "unsatisfactory" reports after environmental inspections. Issues of concern identified in the inspections were raised with SOCOG and the venues were re-inspected to ensure compliance.

During the period 1 September to 4 October 2000, food inspection teams reported details of 6278 food safety inspections of food outlets at Olympic venues, including 2469 compliance audits and 3809 hygiene checks. Of these, 540 compliance audits $(21.9 \%)$ and 245 hygiene checks $(6.4 \%)$ were unsatisfactory, resulting in verbal warnings and follow up inspections. Food vendors voluntarily destroyed 7.5 tonnes of food after they had been advised of food safety risks. This included 7 tonnes of spoiled food from a single food outlet, caused by a refrigeration failure.

\section{Surveillance for bioterrorism}

No incident suggestive of bioterrorism occurred during the Sydney 2000 Olympic Games.

\section{Global epidemic intelligence}

No communicable disease outbreaks that had a direct bearing on Sydney during the Games were reported.

\section{Investigation of public health incidents}

The surveillance system facilitated the timely investigation of, and response to several incidents of possible public health concern, as detailed in table 2 . 


\section{Key points}

- During the Sydney 2000 Olympic Games, there were around $5 \%$ more presentations to emergency departments than in comparable periods in other years.

- Several incidents detected through surveillance, including injuries caused by broken glass, and a cluster of presentations related to the use of the drug ecstasy, prompted further action.

- Key elements in the success of public health surveillance for Games included careful planning, comprehensive coverage, and timely reporting.

- Future public health surveillance systems need to be flexible enough to detect the unexpected.

\section{DISCUSSION}

In his speech at the closing ceremony for the Sydney 2000 Olympic Games, Juan Antonio Samaranch, the President of the IOC, proclaimed that Sydney had hosted the "best Olympic Games ever". We believe that the public health surveillance system made an important contribution to the success of the public health aspects of the Sydney 2000 Olympic Games. Key elements in its success included its careful planning, its comprehensive coverage of public health issues, and its timely reporting and communication processes.

Detailed planning for the surveillance system began almost three years before the Games, allowing sufficient time to fully specify the system, obtain appropriate resources, test system components, and train surveillance staff.

The surveillance system was more comprehensive than that deployed at any previous Olympic Games. Among the new features for the Sydney 2000 Games were the integration of daily data from food safety inspections, environmental inspections, and cruise ship surveillance into the surveillance system. The multiple data sources allowed assessment of trends in all major health risks, and facilitated in depth exploration of any emerging issues. Automated production of highly detailed reports in electronic form allowed surveillance officers to concentrate on interpretation and further analysis of the data rather than on routine reporting tasks. For example, reports of potentially notifiable diseases received via emergency departments were compared with those received through the communicable disease notifications system, and any discrepancies followed up.

All components of the surveillance system provided data on at least a daily basis throughout their operation, permitting identification of any emerging issues within 24 hours. This timeliness proved of particular worth in the investigation of injury and illicit drug related issues identified through emergency department surveillance.

A related strength of the surveillance system was its clearly defined reporting and communication structure. After assessment by experts in public health surveillance, a daily report, highlighting any important issues, was supplied to the peak health decision making body for the Games. Given that interagency approaches are required to prevent or control many public health issues, such a structure was necessary to ensure effective responses.

The findings of public health surveillance indicate that the Sydney 2000 Games had only a small impact on health. There were slightly more presentations to emergency departments than in the corresponding periods in the preceding and following years-an increase that was not observed in Atlanta. ${ }^{4}$ However, only a few of the extra presentations were by overseas visitors. The increased activity may have reflected reduced availability of general practitioner services, as a result of doctors taking holidays. Although several public health incidents were managed during the surveillance period, there was no evidence that these were directly related to the Games.

Similar to the Atlanta Games, no outbreaks of communicable diseases occurred during the Sydney Games. The relative health and wealth of visitors to Sydney for the Games reduced the likelihood of the importation of these diseases. Visitors had limited opportunities for infection with endemic communicable diseases because they spent much of their time in hotels and Olympic venues. Additionally, the incubation period for many communicable diseases means that cases acquired by Games visitors may not have manifested until after their departure.

In retrospect, it would have been useful if emergency departments and other medical facilities participating in the surveillance system had been issued with rapid influenza diagnostic kits to improve the specificity of presentations for "influenza-like illness". ${ }^{15}$ This is important not only for the containment of influenza virus transmission, but also for the detection of bioterrorism incidents, because the prodromal phases of illnesses caused by a number of potential bioterrorism agents is otherwise difficult to distinguish from influenza. ${ }^{16}{ }^{17}$

The findings of public health surveillance during the Games suggest that any future surveillance systems need to be flexible enough to capture information on unexpected issues. Planning focused particularly on enhancing systems for surveillance of communicable diseases. However, the most acute public health issues to emerge related to injuries and illicit drug related events. Data recorded in the free text injury description field in the emergency department surveillance system proved of particular value. This, rather than data collected in any of the categorised fields, enabled identification of injuries caused by broken glass and foot propelled scooters, ${ }^{18}$ and a cluster of presentations apparently related to the use of the drug ecstasy. Any future system should include such a free text facility, and could use automated text data mining and other computational linguistics techniques to more efficiently scan the recorded text and discover patterns and associations within it. ${ }^{19}$ The subsequent incidents of bioterrorism related anthrax in the United States, and the resulting heightened global concern about bioterrorism, have increased the impetus to further develop such methods.

The experience in Sydney will inform the development of public health surveillance systems for future Olympic Games, as well as other similar mass events. Such systems to "watch" the Games will need to adapt to local circumstances, make use of emerging technology and, most importantly, be flexible enough to detect the unexpected.

\section{ACKNOWLEDGEMENTS}

The authors wish to acknowledge the contributions of Ms Maria Visotina, manager of the New South Wales Health Department's Olympic Planning Unit; members of the Olympic Surveillance Working Party; staff of the Olympic Planning Unit, Epidemiology and Surveillance Branch, Communicable Diseases Surveillance and Control Unit and Public Health Officer Training Program; and all other staff of New South Wales Health who were part of the Olympic surveillance effort.

a.......................

Authors' affiliations

L R Jorm, T R Churches, Epidemiology and Surveillance Branch, New South Wales Health Department, Australia

S V Thackway, Division of Population Health and Planning, Illawarra Area Health Service, Australia

M W Hills, Olympic Planning Unit, New South Wales Health Department

Funding: public health surveillance for the Sydney 2000 Olympic Games was funded by the New South Wales Government.

Conflicts of interest: none.

\section{REFERENCES}

1 Weiss BP, Mascola L, Fannin SL. Public health at the 1984 Summer Olympics: the Los Angeles County experience. Am J Public Health 1988;78:686-8 
2 Panella $\mathbf{H}$, Plasecia A, Sanz $M$, et al. Evaluation of the epidemiologic surveillance system for infectious diseases at the Barcelona Olympic Games 1992. Gac Sanit 1995;9:84-90.

3 Meehan P, Toomey KE, Drinnon J, et al. Public health response for the 1996 Olympic Games. JAMA 1998;279:1469-73.

4 Toomey KE. Final report and summary report: epidemiological surveillance system during the 1996 Olympics. Atlanta, GA: Epidemiology and Prevention Branch, Georgia Department of Human Resources, 1996.

5 Anon. Infectious diseases January-February 1998. New South Wales Public Health Bulletin 1998;9:24

6 Anon. The Sydney water incident: July-September 1998. New South Wales Public Health Bulletin 1998;9:92-4.

7 Formica N, Tallis G, Zwolak B, et al. Legionnaires' disease outbreak: Victoria's largest identified outbreak. Communicable Diseases Intelligence 2000;24:199-202.

8 Menzies R. Infectious disease surveillance during the Sydney 2000 Olympic and Paralympic Games. New South Wales Public Health Bulletin 2000;11:146-7.

9 Churches T. Health surveillance at Olympic venues: The Medical Encounter Reporting System. New South Wales Public Health Bulletin 2000;11:145-6.
10 US Public Health Service. Vessel sanitation program operations manual. Atlanta, GA: US Department of Health and Human Services, 1987.

11 Henderson DA. Bioterrorism as a public health threat. Emerging Infectious Diseases 1998:4:488-92.

12 Pavlin JA. Epidemiology of bioterrorism. Emerging Infectious Diseases 1999.5:528-30.

13 SAS. SAS software, version 8.1. Cary, NC: SAS Institute, 2000

14 Anon. Outbreak of influenza-like illness on board a cruise ship. New South Wales Public Health Bulletin 2000;1 1:194-5.

15 Stamboulian D, Bonvehi PE, Nacinovich FM, et al. Influenza. Infect Dis Clin North Am 2000;14:141-66.

16 Schoch-Spana M. Implications of pandemic influenza for bioterrorism response. Clin Infect Dis 2000;31:1409-13.

17 Heddurshetti R, Pumpradit W, Lutwick LI. Pulmonary manifestations of bioterrorism. Current Infectious Disease Reports $2001 ; 3: 249-57$.

18 Jorm LR, Thackway SV. Foot-propelled scooter injuries during the Sydney 2000 Olympic Games period. Med J Aust 2001;174:480.

19 Hearst MA. Untangling text data mining. In: Proceedings of $A C L$ '99: the 37th Annual Meeting of the Association of Computational Linguistics, University of Maryland, June 20-26, 1999. Available at: http://www. sims.berkeley/edu/ hearst/papers/acl99/acl99-tdm.html (accessed 6 July 2001).

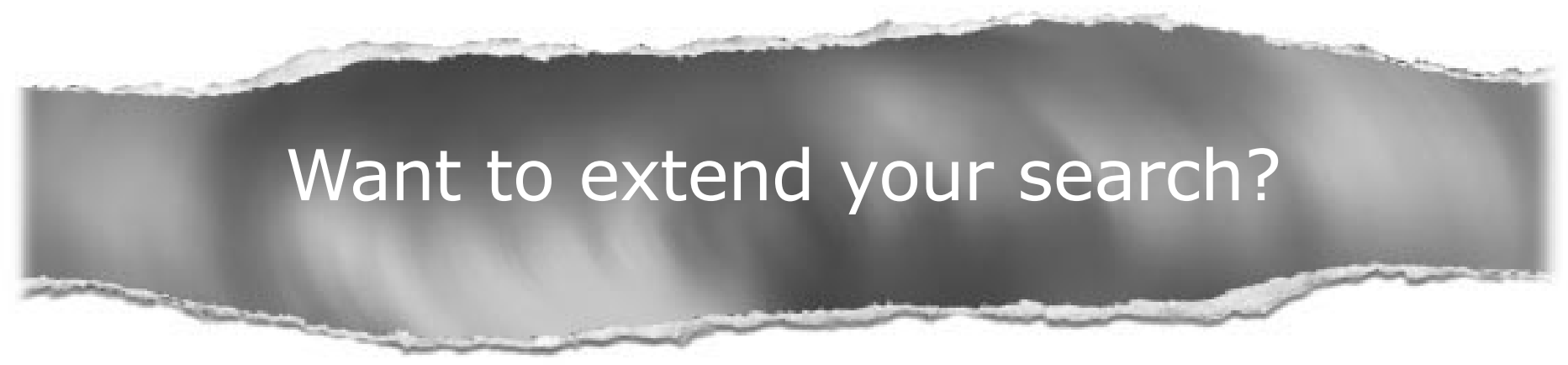

Cross journal searching

If you can't find what you are looking for in the Journal of Epidemiology and Community Health you can extend your search across many of the more than 200 journals available for selection. You can restrict your search to specific subject areas (eg, clinical medicine, basic research), or select specific journals, or search all available titles.

\section{www.jech.com}

